\title{
Comparison of plantain plantlets propagated in temporary immersion bioreactors and gelled medium during in vitro growth and acclimatization
}

\author{
C.E. ARAGÓN ${ }^{1,2}$, C. SÁNCHEZ ${ }^{3}$, J. GONZALEZ-OLMEDO ${ }^{2}$, M. ESCALONA², L. CARVALHO ${ }^{1}$, \\ and $\mathrm{S}$. AMÂNCIO ${ }^{1 *}$
}

Instituto Superior de Agronomia, Universidade Técnica de Lisboa, 1349-017 Lisboa, Portugal ${ }^{1}$

Centro de Bioplantas, Universidad de Ciego de Ávila, 69450 Ciego de Ávila, Cuba ${ }^{2}$

Instituto Nacional de Investigação Agrária e Veterinária, 2784-505 Oeiras, Portugal ${ }^{3}$

\begin{abstract}
The current work compared the physiological characteristics of plantain (Musa AAB) plantlets micropropagated in temporary immersion bioreactors (TIB) and on a gelled medium (GM). The plantlets were evaluated during in vitro growth (in the shoot elongation phase) and at the end of ex vitro acclimatization. TIB improved rooting and gave rise to longer shoots and higher dry mass. Respiration rate was the highest at the beginning of shoot elongation in both the TIB and GM plantlets. Photosynthetic rate in TIB was significantly higher than in GM from the midpoint of acclimatization, whereas a pyruvate kinase (PK) activity was lower. Starch accumulation was $c a$. two fold higher in corms than in leaves and always higher in the TIB than GM plantlets. The higher expression of genes coding for carbon metabolism enzymes PK and phosphoenolpyruvate carboxylase (PEPC) in TIB than in PM indicates a more important role of an autotrophic metabolism in the TIB plantlets when compared to the GM ones. The accumulated reserves were used during the first days of acclimatization leading to the higher survival rates and to the better plant quality of the TIB plantlets.
\end{abstract}

Additional key words: acclimatization, ethylene, Musa spp., PEPC, peroxiredoxins, photosynthesis.

\section{Introduction}

Banana and plantain are included in the genus Musa and most of their agronomic and physiologic properties are similar. Plantain is grown almost exclusively by smallscale-subsistence farmers and plays an important socioeconomic role in many developing countries of the tropics and subtropics (Panis and Thinh 2001). Banana and plantain are usually propagated from suckers and bits (pieces of corm with attached growing points), but export-type commercial companies more commonly use tissue-cultured plantlets free from sucker borne diseases and pests. The interest in the use of liquid media in micropropagation (Ziv 2005), and of temporary immersion bioreactors (TIB) in particular, has increased during the last decade. On average, TIB guarantees better plant quality and higher multiplication rates (Escalona et al. 1999, Lorenzo et al. 2001, Etienne and Berthouly 2002, Aragón et al. 2010). However, conventional micropropagation systems using gelled medium (GM) are still widely used for a high number of crops. Both systems comprise specific aspects that allow good plant growth and favour acclimatization although environmental conditions associated to in vitro growth in either GM or TIB confer specific characteristics to the plantlets which are directly responsible for their ex vitro performance. TIB propagation takes place in automated systems that promote the aeration of containers. This ventilation of the headspace is paramount to remove volatile compounds such as ethylene (Roels et al. 2006) and to promote the recirculation of carbon dioxide necessary for photosynthesis further enhancing autotrophic carbon metabolism in leaves. The metabolic and physiological behavior of TIB-produced plantlets has not yet been studied in depth (Teisson and Alvard 1995, Etienne and Berthouly 2002, Escalona et al. 2003), although it is now known that TIB plantain plantlets cope better with reactive oxygen species (ROS) produced at

Submitted 4 December 2012, last revision 18 July 2013, accepted 30 July 2013.

Abbreviations: BAP - 6-benzylaminopurine; GM - gelled medium; PEPC - phosphoenolpyruvate carboxylase; PK - pyruvate kinase; PPFD - photosynthetic photon flux density; Prxs - peroxiredoxins; SS - starch synthase; ROS - reactive oxygen species; TIB - temporary immersion bioreactors.

Acknowledgements: This research received financial support from the Fundação para a Ciência e Tecnologia grants SFRH/BD/43181/2008 and PEst-OE/AGR/UI0240/2011.

* Corresponding authors; fax: (+351) 213653383, e-mail: samport@isa.utl.pt 
the transfer from in vitro to ex vitro conditions (Aragón et al. 2010).

Once the plantlets are ready for shifting from in vitro conditions, they must be acclimatized to adapt to greenhouse and later to field (Ma and Shii 1974, Martín et al. 2009). During this hardening period, plantlets undergo physiological adaptations to external factors like water availability, temperature, air humidity, and nutrient supply. Starch accumulation in leaves of in vitro plantlets is vital for the acclimation to ex vitro conditions (Capellades et al. 1991, Cayón 2001, Bello-Pérez et al. 2002) and leaves play an important role as carbon source during the transition to autotrophy. Also, particular roles were reported for phosphoenolpyruvate carboxylase (PEPC) and pyruvate kinase (PK) during acclimatization of TIB propagated plantlets, PEPC being responsible for the mobilization of sugars through an anaplerotic route to guarantee the supply of carbon skeletons for amino acid synthesis during in vitro propagation (Aragón et al.
2005). Plantain propagation in TIB was also studied under $\mathrm{CO}_{2}$ enrichment (Aragón et al. 2009) that increased overall plant quality and led to a favourable balance between the starch content in leaves and corms.

The mechanisms by which TIB grown plantlets are able to better sustain and overcome oxidative stress than GM grown plantlets, thus enhancing their propagation capacity and improving their growth, were recently elucidated including the partial characterization and the description of the role of peroxiredoxins (Prxs) in this transition (Aragón et al. 2010). In the current study, in vitro growth of plantain plantlets in TIB and GM is characterized according to ethylene accumulation in the headspace, photosynthetic rate, stomatal conductance, starch accumulation, and PK and PEPC activities. The expression of genes coding these enzymes was monitored during the acclimatization of those plantlets. Finally, gene expression and protein profile of Prx Q, E, and F were analyzed at the end of acclimatization.

\section{Materials and methods}

Plants and in vitro culture: Plantain shoots (Musa AAB cv. Cemsa 3/4) were micropropagated in a gelled medium (GM) containing Murashige and Skoog (1962; MS) salts and vitamins (MS), $30 \mathrm{~g} \mathrm{dm}^{-3}$ sucrose, $13.3 \mu \mathrm{M}$ 6-benzylaminopurine (BAP), and $2.5 \mathrm{~g} \mathrm{dm}^{-3}$ Gelrite for 3 subculture cycles of $28 \mathrm{~d}$. After this, only shoots with a corm diameter of at least $3 \mathrm{~mm}$ and $3 \mathrm{~cm}$ length were used for the elongation phase lasting $21 \mathrm{~d}$. Two different techniques, GM and temporary immersion bioreactors (TIB), were used. In both methods, the basal medium was MS supplemented with $30 \mathrm{~g} \mathrm{dm}^{-3}$ sucrose, without plant growth regulators, with $\mathrm{pH}$ adjusted to 5.8 before autoclaving at $121{ }^{\circ} \mathrm{C}$ and $118 \mathrm{kPa}$ for $20 \mathrm{~min}$. GM plantlets were placed in glass vessels of $500 \mathrm{~cm}^{3}$ total volume containing $150 \mathrm{~cm}^{3}$ of media, jellified with $2.5 \mathrm{~g}$ $\mathrm{dm}^{-3}$ Gelrite, 5 shoots per vessel. TIB was performed in pairs of the same vessels, one vessel containing 5 shoots and the other $150 \mathrm{~cm}^{3}$ of a liquid medium (Escalona et al. 1999). An automatic pump system allowed the forced ventilation of the TIB system with the immersion of the shoots in the media for $4 \mathrm{~min}$ every $3 \mathrm{~h}$ and the subsequent renewal of the headspace. Air pressure from an air compressor pushed the medium from one container to the other to immerse the plants completely. The airflow was reversed to withdraw the medium from the culture container. Atmospheric air with a $\mathrm{CO}_{2}$ concentration of $375 \mu \mathrm{mol} \mathrm{mol}{ }^{-1}$ was used in TIB, and in GM, the $\mathrm{CO}_{2}$ concentration was variable depending on the plant metabolism, as it is a closed system. Cultures were maintained at temperature of $25^{\circ} \mathrm{C}$, a 16-h photoperiod, and a photosynthetic photon flux density (PPFD) of $45 \pm 5 \mu \mathrm{mol} \mathrm{m} \mathrm{m}^{-2} \mathrm{~s}^{-1}$ (cool-white fluorescent lamps Daylight F40T12/D, 40 W, Sylvania, Danvers, USA). The plantlets were harvested weekly during elongation (E0, E7, E14, and E21) for ethylene and morphological and physiological parameter determinations. At each time

point, the following growth parameters were evaluated in 15 plantlets: a shoot length, a diameter of the base of the pseudostem, a number of leaves per shoot, a length and maximum width of the main leaf, a leaf area (LA calculated by the approximation to the ellipse area; Nakamura et al. 2005), a number of roots per shoot, a fresh mass and a dry mass (after drying the whole plants at $50^{\circ} \mathrm{C}$ until a constant mass).

Ex vitro acclimatization: After elongation, the shoots produced in GM and TIB were transplanted to pots containing a sterilized mixture of water saturated peat and Perlite $(1: 1, \mathrm{v} / \mathrm{v})$ and placed in glass chambers $\left(450 \mathrm{dm}^{3}\right.$; 500E, Aralab, Porto Salvo, Portugal). PPFD was $200 \pm 10 \mu \mathrm{mol} \mathrm{m}^{-2} \mathrm{~s}^{-1}$ and a $16-\mathrm{h}$ photoperiod. The initial relative humidity $(\mathrm{RH})$ was set at $98 \%$ and gradually decreased until it reached the ambient value. Temperature was $25 \pm 2{ }^{\circ} \mathrm{C}$ during the day and $22 \pm 1{ }^{\circ} \mathrm{C}$ during the dark period. The plants were sampled after $0,3,7$, and $14 \mathrm{~d}$ of acclimatization (A0, A3, A7, and A14) for the expression of genes coding PK, PEPC, and SS. At the end of acclimatization (A21), the peroxiredoxin gene expression was quantified. One time point was coincidental between elongation and acclimatization $(\mathrm{E} 21=\mathrm{A} 0)$ and the whole experiment lasted $42 \mathrm{~d}(21+21)$.

Quantification of ethylene in the headspaces: An ethylene concentration in the headspaces was determined by gas chromatography. Samples of the headspace atmosphere were taken with a syringe and needle perforating the silicone tube connecting the vessel pairs in the TIB systems or protruding from the GM vessels. The samples were injected in sealed rubber cap vials until total atmosphere was renovated. For each time point, at least three independent samples $\left(1 \mathrm{~cm}^{3}\right)$ were analyzed in a gas chromatograph (PYE Unicam 204, Cambridge, UK) 
equipped with a flame ionization detector (FID) and a Porapak $Q$ column (80 - 100 mesh, $1.5 \mathrm{~m}$ length, and $4 \mathrm{~mm}$ diameter). Nitrogen was used as carrier gas at a flow rate of $30 \mathrm{~cm}^{3} \mathrm{~min}^{-1}$, and the injector, column, and detector temperatures were 25,100 , and $150{ }^{\circ} \mathrm{C}$, respectively. An external ethylene standard $\left(29 \mathrm{~mm}^{3} \mathrm{dm}^{-3}\right)$ was used as reference.

Photosynthetic rate, stomatal conductance, and transpiration rate: During the elongation phase, fully expanded leaves were sampled weekly in the middle of the photoperiod. The gas exchange parameters were recorded with a portable $C I R A S-2$ photosynthesis system (PP Systems, Herts, UK). The leaf used occupied the whole area of the cuvette $\left(P L C 6 ; 2.5 \mathrm{~cm}^{2}\right)$. The $\mathrm{CO}_{2}$ concentration and the humidity of the air entering the leaf chamber were $375 \mu \mathrm{mol} \mathrm{mol} \mathrm{m}^{-1}$ and $80 \%$, respectively, PPFD was $600 \mu \mathrm{mol} \mathrm{m} \mathrm{m}^{-2} \mathrm{~s}^{-1}$ (maximum at which photosynthesis was stable), and an ambient temperature of $25{ }^{\circ} \mathrm{C}$. Measurements of a photosynthetic rate, stomatal conductance, and transpiration rate were performed on leaves of three plantlets, with 10 measurements per plantlet $(n=30)$.

Starch quantification: Starch content of the corms and leaves was determined in the in vitro and ex vitro grown plantlets. One gram of leaf material was frozen in liquid nitrogen and ground with a mortar and a pestle. Soluble sugars were removed with $80 \%(\mathrm{v} / \mathrm{v})$ ethanol. The extract was centrifuged at $10000 \mathrm{~g}$ and $4{ }^{\circ} \mathrm{C}$ for $20 \mathrm{~min}$ and the pellet was suspended in $5 \mathrm{~cm}^{3}$ of $0.2 \mathrm{M} \mathrm{KOH}$. After the alkaline hydrolyses, an enzymatic treatment with $\beta$-amyloglucosidase (EC 3.2.1.3, Sigma-Aldrich, St. Louis, USA) was applied for total starch degradation (Thomas et al. 1983). Soluble sugars derived from the starch degradation were measured by the anthrone method (Van Handel 1968) using a spectrophotometer Ultrospec II, (GE Healthcare, Little Chalfont, UK) at $620 \mathrm{~nm}$ using potato starch (Sigma-Aldrich) as standard.

Protein extraction and enzyme activity assays: Leaves $(0,25 \mathrm{~g})$ were collected in the middle of the photoperiod and immediately frozen in liquid nitrogen. The frozen samples were ground with a mortar and a pestle and the resulting powdered plant material was resuspended in $1 \mathrm{~cm}^{3}$ of a $50 \mathrm{mM}$ Hepes-KOH buffer containing $12 \mathrm{mM}$ $\mathrm{MgCl}_{2}, 1 \mathrm{mM}$ ethylene glycol-bis ( $\beta$-aminoethyl ether)$N, N$-tetraacetic acid (EGTA), $1 \mathrm{mM}$ ethylenediaminetetraacetic acid (EDTA), $1 \mathrm{mM}$ dithiothreitol (DTT), $10 \%(\mathrm{v} / \mathrm{v})$ glycerol, $2 \mathrm{mM}$ benzamidine, and $2 \mathrm{mM}$ amino- $n$-caproic acid, pH 7.4 according to Siegel and Stitt (1990). The extract was filtered through Miracloth and centrifuged at $15000 \mathrm{~g}$ and $4{ }^{\circ} \mathrm{C}$ for $20 \mathrm{~min}$. Supernatants were desalted through $P D-10$ columns (GE-Healthcare Life Sciences, Buckinghamshire, UK) and used for all the determinations. Protein was quantified by the method of Bradford (1976).

Phosphoenolpyruvate carboxylase (PEPC; EC 4.1.1.31) was immediately measured spectrophotometrically by coupling the reaction to NADH oxidation mediated by malate dehydrogenase. The standard assay solution contained $50 \mathrm{mM}$ Tris- $\mathrm{HCl}(\mathrm{pH}$ 7.6) complemented with $20 \mu \mathrm{M} \mathrm{NaHCO}, 130 \mathrm{nM} \mathrm{NADH}, 10 \mu \mathrm{M} \mathrm{MgCl}, 5 \mu \mathrm{M}$ DTT, $1 \mathrm{U}$ malate dehydrogenase (MDH) (EC 1.1.1.37) (Sigma-Aldrich), $1 \mathrm{mM}$ glucose-6-phospate, $50 \mathrm{~mm}^{3}$ of the desalted enzyme solution in a final volume of $1 \mathrm{~cm}^{3}$. Reactions were initiated by addition of $3.25 \mu \mathrm{M}$ phosphoenolpyruvate (adapted from Geigenberger and Stitt 1991). The reaction was assayed at $25^{\circ} \mathrm{C}$ by monitoring the consumption of NADH at $340 \mathrm{~nm}$ using the spectrophotometer Ultrospec II (Hdider and Desjardins 1994).

Pyruvate kinase (PK; EC 2.7.1.40) was assayed in a reaction coupled with the lactate dehydrogenase $(\mathrm{LDH}$, EC 1.1.1.37) (Sigma-Aldrich) reaction at $25{ }^{\circ} \mathrm{C}$ by monitoring NADH consumption at $340 \mathrm{~nm}$. The assay solution contained $50 \mathrm{mM}$ imidazole- $\mathrm{HCl}$ complemented with $2 \mathrm{mM}$ PEP, $2 \mathrm{mM}$ ADP, $10 \mathrm{mM} \mathrm{MgCl}, 30 \mathrm{mM}$ $\mathrm{KCl}, 0.15 \mathrm{mM} \mathrm{NADH}$, and $2.5 \mathrm{U} \mathrm{cm}^{-3}$ of desalted rabbit muscle LDH (EC 1.1.1.27) (Sigma-Aldrich) in a final volume of $1 \mathrm{~cm}^{3}$ at $\mathrm{pH} 7.0$ (Lin et al. 1989). Both activities were expressed in units, with $1 \mathrm{U}=1 \mu \mathrm{mol}$ NADH oxidized per min. Three readings of each sample were performed.

Protein extraction and two-dimensional electrophoresis (2-DE): Frozen leaf material ( $0.5 \mathrm{~g})$ previously collected at day 21 of acclimatization in the middle of photoperiod was ground in the presence of liquid nitrogen. Proteins were precipitated at $-20{ }^{\circ} \mathrm{C}$ for $1 \mathrm{~h}$ with acetone containing $10 \%(\mathrm{~m} / \mathrm{v})$ trichloroacetic acid (TCA) and $60 \mathrm{mM}$ DTT, and centrifuged at $15000 \mathrm{~g}$ and at $4{ }^{\circ} \mathrm{C}$ for $15 \mathrm{~min}$. The resulting pellet was washed with acetone containing $60 \mathrm{mM}$ DTT at $-20{ }^{\circ} \mathrm{C}$ for $1 \mathrm{~h}$ and centrifuged again. This pellet was dried under vacuum and used as crude extract after being re-dissolved at $25^{\circ} \mathrm{C}$ for $2 \mathrm{~h}$ in a buffer containing $7 \mathrm{M}$ urea, $2 \mathrm{M}$ thiourea, $0.4 \%$ (v/v) Triton $X-100,4 \%(\mathrm{~m} / \mathrm{v}) \quad 3-[(3-c h o l a m i d o p r o p y l)-$ dimethyl-ammonio]-1-propane sulfonate (CHAPS), $60 \mathrm{mM}$ DTT, and a $1 \%(\mathrm{v} / \mathrm{v})$ immobilized $\mathrm{pH}$ gradient buffer (IPG; GE Healthcare Life Sciences). Protein was quantified by the method of Bradford (1976), modified by Ramagli (1999). The samples were incubated at $25^{\circ} \mathrm{C}$ for $1 \mathrm{~h}$ in a re-hydration buffer containing $8 \mathrm{M}$ urea, $4 \%$ $(\mathrm{m} / \mathrm{v})$ CHAPS, $60 \mathrm{mM}$ DTT, and $1 \%$ (v/v) IPG buffer.

Isoelectric focusing (IEF) was carried out using Ready-Strip-IPG-Strips (Bio-Rad, Hercules, USA) with linear $\mathrm{pH}$ gradient $3-10$ and $40 \mathrm{mg}$ of each protein sample were loaded. The IEF was carried out using a Protean i12 IEF cell (Bio-Rad) with rehydration at $50 \mathrm{~V}$ for $12 \mathrm{~h}$, followed by four consecutive steps in the following conditions: $250 \mathrm{~V} \mathrm{~h}^{-1}, 500 \mathrm{~V} \mathrm{~h}^{-1}, 8000 \mathrm{~V}$ for $2.30 \mathrm{~h}$, and $8000 \mathrm{~V} \mathrm{~h}^{-1}$ until reaching $30000 \mathrm{~V}$. Then the IEF strips were equilibrated for $15 \mathrm{~min}$ in $50 \mathrm{mM}$ Tris$\mathrm{HCl}, \mathrm{pH} 8.8$, containing $6 \mathrm{M}$ urea, $30 \%(\mathrm{v} / \mathrm{v})$ glycerol, $1 \%(\mathrm{~m} / \mathrm{v}) \mathrm{SDS}$, and $65 \mathrm{mM}$ DTT. To remove DTT excess, strips were equilibrated in the same buffer for 
15 min replacing DTT with $135 \mathrm{mM}$ iodoacetamide. SDS-PAGE in the second dimension was then performed in denaturing polyacrylamide gels according to the procedure of Laemmli (1970) without stacking gel.

Immunoblotting: Polyclonal antibodies against chloroplast-located type II Prx E, chloroplast-located Prx Q, and mitochondria-located type II Prx F were kindly supplied by Professor K-J Dietz (Bielefeld University, Bielefeld, Germany). A Western blot analysis was performed after 2-DE through the transfer of proteins to a nitrocellulose membrane (Millipore). The membranes were probed with the respective antibodies using the procedure described by Ferreira et al. (1996) and staining was performed with an $A P$ conjugate substrate kit (Bio-Rad).

RNA isolation and cDNA preparation: Total RNA from frozen leaf material collected along the acclimatization phase (A0, A3, A7, and A14) was extracted by adapting the method of Chang et al. (1993). An extraction buffer consisted of cetyltrimethylamonnium bromide (CTAB; $2 \%, \mathrm{~m} / \mathrm{v}$ ) complemented with polyvinylpolypyrrolidone (PVPP; $2 \%, \mathrm{~m} / \mathrm{v}$ ), 100 $\mathrm{mM}$ Trizma-HCl, $25 \mathrm{mM} \mathrm{Na}{ }_{2}$ EDTA, and $2 \mathrm{M} \mathrm{NaCl}, \mathrm{pH}$ 8.0 , heated to $85^{\circ} \mathrm{C}$ prior to the addition of $400 \mathrm{~mm}^{3}$ of 2-mercaptoethanol. Tissues were ground to powder in liquid $\mathrm{N}_{2}$ and $20 \mathrm{~cm}^{3}$ of the extraction buffer was added. The same volume of chloroform:isoamyl alcohol 24:1 was then added. This step was followed by centrifugation at $12000 \mathrm{~g}$ and $20^{\circ} \mathrm{C}$ for $30 \mathrm{~min}$ and repeated once. The aqueous phase was transferred to a new tube, and 0.25 volumes of $10 \mathrm{M} \mathrm{LiCl}$ was added. The sample was incubated at $0{ }^{\circ} \mathrm{C}$ overnight and after centrifugation at $12000 \mathrm{~g}$ and $4{ }^{\circ} \mathrm{C}$ for $20 \mathrm{~min}$, the pellet was recovered. A $1.5 \mathrm{~cm}^{3}$ volume of buffer $(10 \mathrm{mM}$ Trizma- $\mathrm{HCl}, 1 \mathrm{mM}$ $\mathrm{Na}_{2}$ EDTA, $1 \mathrm{M} \mathrm{NaCl}$, and $0.5 \%, \mathrm{~m} / \mathrm{v}$, sodiumdodecyl sulphate, SDS, $\mathrm{pH} 8.0$, previously heated to $37{ }^{\circ} \mathrm{C}$ ) was added. Ethanol (100\%, 2.5 volumes) was added and the samples were incubated at $-80^{\circ} \mathrm{C}$ for $1 \mathrm{~h}$ and then washed with $70 \%(\mathrm{v} / \mathrm{v})$ ethanol. After drying, the RNA was resuspended in the desired volume of distilled water.

RNA samples were treated with $R Q 1$ RNase-free DNase (Promega, Madison, WI, USA). cDNA was synthesized from $2 \mu \mathrm{g}$ of total RNA using oligo (dT) in a $20 \mathrm{~mm}^{3}$ reaction volume with revert aid reverse transcriptase (Fermentas Life Science, Helsingborg, Sweden) according to the manufacturer's recommendations.

Real time PCR: Primer pairs used for amplification of the genes studied are presented in Table 1. The genomic sequences for plantain available in the GeneBank database (http://www.ncbi.nlm.nih.gov/genbank/) were used and when plantain sequences were not available, the respective orthologs of Vitis vinifera, previously tested by our group, were used.

A $20 \mathrm{~mm}^{3}$ volume of the reaction mixture was composed of cDNA, $0.5 \mu \mathrm{M}$ gene-specific primers and a master mix iQ EVA Green Supermix (Bio-Rad) and iQ5 real time PCR (Bio-Rad) was used. Amplification of PCR products was monitored via intercalation of EVA Green (included in the master mix). The following program was applied: initial polymerase activation at $95^{\circ} \mathrm{C}$ for $3 \mathrm{~min}$, then 40 cycles at $95{ }^{\circ} \mathrm{C}$ for $15 \mathrm{~s}$ (denaturation), at $57{ }^{\circ} \mathrm{C}$ for $30 \mathrm{~s}$ (annealing), and at $72{ }^{\circ} \mathrm{C}$ for $20 \mathrm{~s}$ (extension) with single fluorescence reading taken at the end of each cycle. Each run was completed with a melting curve analysis to confirm the specificity of amplification and the lack of primer dimers. Further, PCR products were resolved on $2 \%(\mathrm{~m} / \mathrm{v})$ agarose gels run at $4 \mathrm{~V} \mathrm{~cm}^{-1}$ in a Tris-acetate-EDTA buffer (TAE) together with a 50-bp DNA-standard ladder (Invitrogen) to confirm the presence of a single product of the desired length.

To generate a baseline-subtracted plot of the logarithmic increase in fluorescence signal $(\Delta R n)$ versus a cycle number, baseline data were collected between the cycles 5 and 17. All amplification plots were analyzed with an $\mathrm{Rn}$ threshold of 0.3 to obtain $\mathrm{Cq}$ (quantification cycle) and the data obtained were exported into a $M S$ Excel workbook. In order to compare data from different PCR runs or cDNA samples, $\mathrm{Cq}$ values were normalized to the $\mathrm{Cq}$ value of $A c t 2$, a housekeeping gene expressed at a relatively high and constant level (Coito et al. 2012) and the $\Delta \Delta \mathrm{Cq}$ method was used for the quantification of gene expression.

Statistical analysis of the results: Each experiment was performed twice and the combined results of both experiments were analyzed. The number of replicates performed is indicated in the legends of figures and tables. Statistical analyses were carried out using SPSS v. 12 (Pérez 2005) and the treatments were compared using the non-parametric analysis by Kruskall-Wallis, Dunnett, or Mann Whitney tests at $5 \%$ probability.

\section{Results}

In the present study, plantain plantlets propagated in the TIB and GM conditions were compared during in vitro growth and during acclimatization.

The ethylene concentration in the headspace of the GM and TIB systems was analyzed (Table 2). In GM, an increase began at E14 and reached $0.11 \mathrm{~mm}^{3} \mathrm{dm}^{-3}$ in the last week. Conversely, in the headspace of the TIB cultures, ethylene was only detected at E21 and its

concentration was significantly lower $\left(0.02 \mathrm{~mm}^{3} \mathrm{dm}^{-3}\right)$.

At the end of the elongation phase, the TIB propagated plantlets had significantly longer shoots and main leaves, a higher number of leaves and roots, and higher fresh and dry masses when compared to the GM grown plantlets (Table 2 ). In the TIB cultures, a high rate of plant growth during the first weeks often occurred, slowing down towards the end when the stem diameter 
Table 1. RT-qPCR primers used for gene expression (sequences from plantain or from grape vine).

\begin{tabular}{|c|c|c|c|}
\hline Protein & Acc. number & Primer & Sequence \\
\hline Actin & AF369525.1 & ACT-F & 5'-TGGATTCTGGTGATGGTGTGAGTC-3' \\
\hline Vitis & & ACT-R & 3'-CAATTTCCCGTTCAGCAGTAGTGG-5' \\
\hline Pyruvate kinase 1 & Mu11M06 14 & PK1-F & 5'-TTCACAACACACCTGGAGAACC-3' \\
\hline Musa & & PK1-R & 5'-GATGTCACCTCCTCCTCGTCTG-3' \\
\hline Phosphoenolpyruvate carboxylase & Z99987.1 & PEPC-F & 5'-GGTAGTGGAAATGTCTCGCTTGG-3' \\
\hline Musa & & PEPC-R & 5'-GGCTTCTCAGGTTCATGGATTGC-3' \\
\hline Starch synthase & JQ861709 & SS-F & 5'-AATCTCACGGGATATACAAGAATGC-3' \\
\hline Musa & & SS-R & 5'-GCCTGTTAGACCCATCAGTGAAATC-3' \\
\hline Type II peroxiredoxin E & JN392723 & PrxE-F & 5'-AATCTACCATAGGAATGCTCGTTGC-3' \\
\hline Vitis & & PrxE-R & 3'-AATCAGACACAGGAAACCACAAACC-5' \\
\hline Type II peroxiredoxin F & JN392724 & PrxF-F & 5'-CGAAGCATGATGATGAAATCAACGG-3' \\
\hline Vitis & & PrxF-R & $3^{\prime}$-GCACCAGAAACCTTAACCTCGGATG-5' \\
\hline Peroxiredoxin Q & JN392725 & PrxQ-F & 5'-ACCTTCCTCACTCTTAATGGCTTCC-3' \\
\hline Vitis & & PrxQ-R & 3'-CTTTCCTCACCTTGTTTCCGTCATC-5' \\
\hline
\end{tabular}

Table 2. Effect of the micropropagation system (GM or TIB) on plantain ethylene content in headspace $(n=3)$, morphology $(n=15)$, photosynthetic rate, stomatal conductance, and transpiration rate $(n=30)$, starch content in leaves and corms, and activity of pyruvate kinase (PK) and posphoenolpyruvate carboxylase (PEPC) $(n=9)$ during in vitro elongation measured at days $0,7,14$, and 21 . Values followed by different letters within each row are significantly different at $5 \%$ level. One unit (U) corresponds to $1 \mu$ mol of substrate processed per hour. * - Vestigial concentrations of ethylene measured, impossible to quantify.

\begin{tabular}{|c|c|c|c|c|c|c|c|}
\hline Parameters & E0 & $\begin{array}{l}\text { E7 } \\
\text { GM }\end{array}$ & TIB & $\begin{array}{l}\text { E14 } \\
\text { GM }\end{array}$ & TIB & $\begin{array}{l}\text { E21 } \\
\text { GM }\end{array}$ & TIB \\
\hline Ethylene $\left[\mathrm{mm}^{3} \mathrm{dm}^{-3}\right]$ & control & * & * & $0.024 \mathrm{~b}$ & * & $0.112 \mathrm{a}$ & $0.019 \mathrm{~b}$ \\
\hline Shoot length $[\mathrm{cm}]$ & $3.02 \mathrm{c}$ & $3.23 \mathrm{c}$ & $3.17 \mathrm{c}$ & $3.63 \mathrm{~b}$ & $4.19 \mathrm{a}$ & $3.85 \mathrm{~b}$ & $4.18 \mathrm{a}$ \\
\hline Stem diameter $[\mathrm{cm}]$ & $0.41 \mathrm{c}$ & $0.51 \mathrm{~b}$ & $0.53 \mathrm{~b}$ & $0.57 \mathrm{~b}$ & $0.56 \mathrm{~b}$ & $0.73 \mathrm{a}$ & $0.71 \mathrm{a}$ \\
\hline Number of leaves per shoot & $1.40 \mathrm{c}$ & $2.07 \mathrm{~b}$ & $2.27 \mathrm{~b}$ & $2.33 \mathrm{~b}$ & $2.73 \mathrm{a}$ & $2.07 \mathrm{~b}$ & $2.80 \mathrm{a}$ \\
\hline Length of main leaf $[\mathrm{cm}]$ & $1.49 \mathrm{c}$ & $2.09 \mathrm{~b}$ & $1.75 \mathrm{c}$ & $2.18 \mathrm{~b}$ & $2.57 \mathrm{a}$ & $2.04 \mathrm{~b}$ & $2.46 \mathrm{a}$ \\
\hline Width of main leaf [cm] & $0.86 \mathrm{~b}$ & $1.06 \mathrm{ab}$ & $0.79 \mathrm{~b}$ & $1.21 \mathrm{a}$ & $0.93 \mathrm{~b}$ & $1.15 \mathrm{a}$ & $0.97 \mathrm{~b}$ \\
\hline Leaf area $\left[\mathrm{cm}^{2}\right]$ & $1.28 \mathrm{~b}$ & $2.21 \mathrm{ab}$ & $1.38 \mathrm{~b}$ & $2.63 \mathrm{a}$ & $2.39 \mathrm{a}$ & $2.34 \mathrm{a}$ & $2.38 \mathrm{a}$ \\
\hline Number of roots per shoot & $0.00 \mathrm{c}$ & $0.00 \mathrm{c}$ & $0.00 \mathrm{c}$ & $0.00 \mathrm{c}$ & $1.80 \mathrm{~b}$ & $1.60 \mathrm{~b}$ & $2.93 \mathrm{a}$ \\
\hline Fresh mass $[\mathrm{g}]$ & $0.67 \mathrm{~b}$ & $0.60 \mathrm{~b}$ & $0.49 \mathrm{c}$ & $0.71 \mathrm{~b}$ & $0.86 \mathrm{a}$ & $0.77 \mathrm{~b}$ & $0.86 \mathrm{a}$ \\
\hline Dry mass $[\mathrm{g}]$ & $0.03 \mathrm{~b}$ & $0.03 \mathrm{~b}$ & $0.03 \mathrm{c}$ & $0.04 \mathrm{~b}$ & $0.04 \mathrm{a}$ & $0.04 \mathrm{~b}$ & $0.04 \mathrm{a}$ \\
\hline Photosynthetic rate $\left[\mu \mathrm{mol}\left(\mathrm{CO}_{2}\right) \mathrm{m}^{-2} \mathrm{~s}^{-1}\right]$ & $-7.63 c$ & $-10.92 \mathrm{c}$ & $-12.59 \mathrm{c}$ & $1.92 \mathrm{~b}$ & $8.86 \mathrm{a}$ & $2.12 b$ & $6.04 \mathrm{a}$ \\
\hline Stomata conductance $\left[\mathrm{mol}\left(\mathrm{H}_{2} \mathrm{O}\right) \mathrm{m}^{-2} \mathrm{~s}^{-1}\right]$ & $0.16 \mathrm{~b}$ & $0.17 \mathrm{~b}$ & $0.15 \mathrm{~b}$ & $0.33 \mathrm{a}$ & $0.05 \mathrm{c}$ & $0.39 \mathrm{a}$ & $0.06 \mathrm{c}$ \\
\hline Transpiration rate $\left[\mathrm{mmol}\left(\mathrm{H}_{2} \mathrm{O}\right) \mathrm{m}^{-2} \mathrm{~s}^{-1}\right]$ & $1.33 \mathrm{~b}$ & $0.81 \mathrm{c}$ & $2.17 \mathrm{a}$ & $1.34 \mathrm{~b}$ & $1.56 \mathrm{~b}$ & $1.29 \mathrm{~b}$ & $1.90 \mathrm{a}$ \\
\hline Starch, leaves $\left[\mathrm{g} \mathrm{g}^{-1}\right.$ (d.m.) $]$ & $0.00 \mathrm{e}$ & $0.37 \mathrm{c}$ & $0.00 \mathrm{e}$ & $0.39 \mathrm{c}$ & $0.04 \mathrm{~d}$ & $0.90 \mathrm{~b}$ & $1.51 \mathrm{a}$ \\
\hline Starch, corm $\left[\left(\mathrm{mg} \mathrm{g}^{-1}\right.\right.$ (d.m. $\left.)\right]$ & $1.15 \mathrm{~b}$ & $0.57 \mathrm{c}$ & $1.16 \mathrm{~b}$ & $1.06 \mathrm{~b}$ & $0.59 \mathrm{c}$ & $3.27 \mathrm{a}$ & $3.59 \mathrm{a}$ \\
\hline $\mathrm{PK}\left[\mathrm{U} \mathrm{mg}^{-1}\right.$ (prot.) $]$ & $22.29 \mathrm{~d}$ & $284.6 \mathrm{c}$ & $15.43 \mathrm{~d}$ & $411.55 \mathrm{~b}$ & $34.57 \mathrm{~d}$ & $501.25 \mathrm{a}$ & $50.62 \mathrm{~d}$ \\
\hline PEPC [U mg ${ }^{-1}$ (prot.) $]$ & $6.31 \mathrm{c}$ & $6.33 \mathrm{c}$ & $15.08 \mathrm{a}$ & $10.34 \mathrm{~b}$ & $18.51 \mathrm{a}$ & $12.06 \mathrm{~b}$ & $17.85 \mathrm{a}$ \\
\hline
\end{tabular}

increased by accumulation of reserves, and roots protruded and expanded (Table 2). For the same leaf area (LA), GM favoured the growth of the plantlets with wide and short leaves, whereas TIB gave rise to longer and thinner leaves. Most of the morphological parameters changed mostly during the first $14 \mathrm{~d}$ of elongation with two exceptions: the stem diameter which increased in the last week and was not affected by the propagation method; and the number of roots per shoot because roots protruded on day 14 in the TIB and not before day 21 in the GM plantlets.

Photosynthetic and transpiration rates were measured during elongation in plantlets grown under the GM and TIB (Table 2). Until E7, negative values of $\mathrm{CO}_{2}$ uptake were measured, an indicator of respiratory activity. From that time point on, the plantlets were photosynthetically active with a net photosynthetic rate 3 - to 4 -fold higher in TIB than in GM. Stomatal conductance of the GM grown plantlets increased during the elongation phase, with a significant rise at E14. Conversely, in the TIB grown plantlets, stomatal conductance decreased during elongation, attaining values of one sixth of that in the GM plantlets. However, the transpiration rate in the TIB plantlets was high, certainly due to the constant aeration of the headspace and so much lower air humidity.

The maximum starch accumulation in the corms and leaves was observed on day 21 of elongation, with no differences between GM and TIB in the corms, but higher 
values in the leaves of the TIB plantlets as compared to GM (Table 2).

During the elongation period, the PK activity increased steadily in leaves of both the GM and TIB plantlets, although the values were significantly higher in GM (Table 2). The PEPC activity also increased during elongation in both TIB and GM leaves, conversely to PK, PEPC values were significantly higher in the leaves of the TIB plantlets.

Monitoring the expression of the genes encoding PEPC, PK, and starch synthase (SS) during the acclimatization phase $(0,3,7$, and $14 \mathrm{~d})$ in the GM and

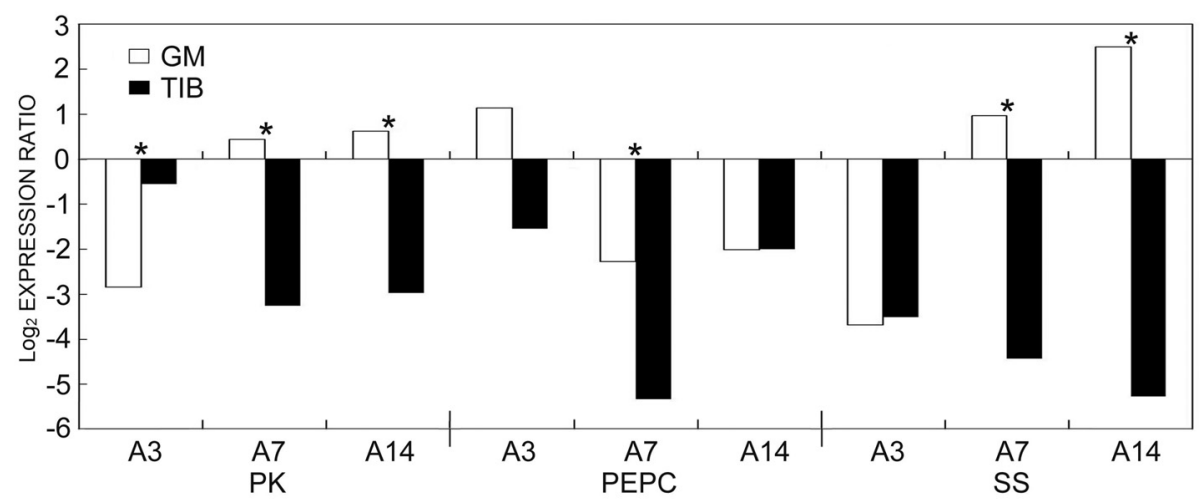

Fig. 1. Patterns of expression of three carbon metabolism genes coding pyruvate kinase (PK), phosphoenolpyruvate carboxylase ( PEPC), and starch synthase (SS) during acclimatization. Expression was obtained by RT-qPCR monitored during the first $14 \mathrm{~d}$ of acclimatization (A3, A7, and A14) after in vitro growth in GM and TIB. Expression was normalized to that of actin 2 and reported 1 at day 0 of acclimatization (* - significant differences at $5 \%$ probability determined by Dunnett multiple range test, $n=4$ ). Positive and negative values were processed separately, for negative values, the positive modular equivalent number was used.

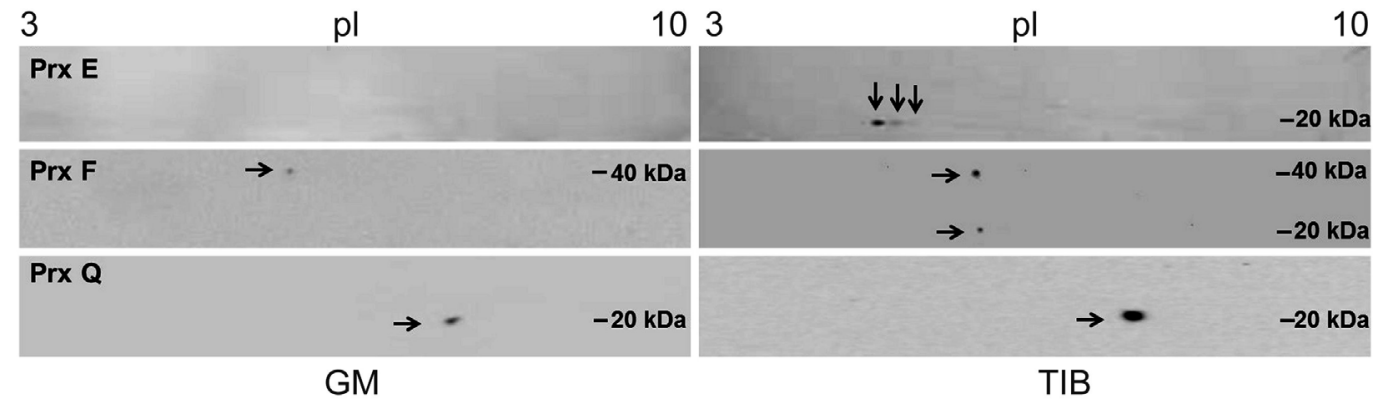

Fig. 2. Comparison of Western blots of three peroxiredoxins (Prx E, F, and Q) in plantain plants propagated in GM and TIB on day 21 of acclimatization. 2-DE gels were transferred to nitro-cellulose membranes and probed with anti-Prx E, F, and Q antibodies, respectively. Arrows indicate the isoforms. First dimension, IEF (left to right, pI 3.0 - 10.0); second dimension, SDS-PAGE (top to bottom). Protein markers in $\mathrm{kDa}$ are indicated at the side of the gels.

TIB grown plantlets (Fig. 1) can give an insight into reprogramming occurring in carbon metabolism when plantlets endured the stress of transition to ex vitro conditions. In GM, $P K$ suffered an initial decrease, returning to the basal level after $7 \mathrm{~d}$, whereas in TIB the decrease was steady and values remained low until day 14 (Fig. 1). The trends of PEPC expression (Fig. 1) were similar to those in PK in the both types of plantlets except for TIB at the $7^{\text {th }}$ day of acclimatization where a significant down-regulation was observed. In accordance, the TIB grown plantlets also showed a significant decrease in $S S$ expression during the whole period of acclimatization, whereas a continuous up-regulation was established in the GM plantlets after the lowest values measured on the third day (Fig. 1).

Total proteins from leaf samples collected on day 21 of acclimatization were separated by $2 \mathrm{D}$ electrophoresis and peroxiredoxins (Prxs) E, F, and Q were identified by immunoblotting. TIB showed a larger number and diversity of Prx spots (Fig 2). Three spots corresponding to Prx E were identified, with a molecular mass $c a$. $20 \mathrm{kDa}$ and $\mathrm{pI} 5-6$ increasing in visual intensity as pI decreased. In the GM grown plants, Prx F had a spot at pI 5.6, Mr ca. $20 \mathrm{kDa}$, and formed a dimer of $40 \mathrm{kDa}$. Prx Q showed a spot of high intensity close to pI 5.4 and $\mathrm{Mr} c a$. $20 \mathrm{kDa}$, and spots of lower intensity were also visualized. The Mr and pI were within the expected ones for Prxs in general (Dietz 2003).

The expression of $\operatorname{Prx} E$, $\operatorname{Prx} F$, and $\operatorname{Prx} Q$ genes at the end of acclimatization (21 d) was monitored (Fig. 3). $\operatorname{Prxs} E$ and $F$ were moderately down-regulated in GM, whereas $\operatorname{Prx} Q$ was strongly up-regulated in the TIB plants. The expression of all Prxs monitored was significantly higher in the TIB than in GM grown plants. 


\section{Discussion}

The present work aimed to assess the influence of the in vitro cultivation method (TIB or GM) on the subsequent ex vitro acclimatization of plantain plantlets. The advantages of TIB on plantain morphology during acclimatization were previously described, focusing on physiological parameters and carbon source storage that could be used during the first days of ex vitro growth (Aragon et al. 2005), and also on the antioxidative response (Aragon et al. 2010).

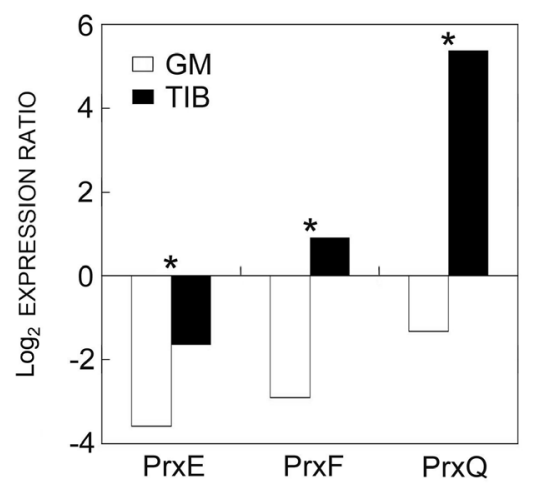

Fig. 3. Quantification of $P r x$ gene expression by RT-qPCR (Prxs $E, F, Q$ ) at the end of acclimatization (A21) of plantain plants previously propagated in GM and TIB. Expression was normalized to that of actin 2 and is reported 1 at day 0 of acclimatization $(*$ - significant differences between expression levels of each Prx in the GM and TIB grown plants at $5 \%$ probability determined by the Dunnett multiple range test, $n=4$ ). Positive and negative values were processed separately, for negative values, the positive modular equivalent number was used.

Plants propagated in TIB showed morphological parameters similar to those obtained by Roels et al. (2005). They had thinner and longer leaves than the GM plants, a feature similar to naturally grown plantain plants. In fact, the observed differences in growth and also in the physiological parameters between the TIB and GM plantlets can be considered a direct result of the propagation method. In TIB, there is a direct contact of the culture medium with the leaves, leading to the possibility of nutrient uptake by them, what does not happen in GM (Escalona et al. 2003, Ziv 2005). This favors the growth of longer leaves that have a higher surface of contact with the medium. During the first period of in vitro culture, the plants are more dependent on the nutrients supplied by the culture media than upon autotrophic nutrition (Moreira et al. 2003, Larema et al. 2012). However, the net photosynthetic rate was higher in the TIB grown plants and the transition from prevailing respiration to photosynthesis was slower in the GM plants. Furthermore, TIB methodology induced a decrease in stomatal conductance, a feature closely related with stomata functioning and regulation of gas exchange. The TIB grown plants have a better regulation of stomatal function and can therefore better control loss of water in the first period of acclimatization, overcoming one of the most frequent causes of plant death at that moment (Hazarika 2003, Perveen et al. 2013).

It has been reported previously that the environmental conditions in TIB have a vital influence on growth, physiology, and carbon metabolism of plantain leaves (Aragon et al. 2005). These features can certainly explain the significantly larger size and robustness of TIB grown plantlets. One of the main causes for this can be the continuous renewal of the atmosphere surrounding the plantlets, thus allowing the elimination of ethylene in the culture headspace, which was almost undetectable in the TIB vessels, confirming the results previously obtained by Roels et al. (2006). Several authors have reported ethylene as a stress-causing compound for plants, impairing normal growth, gas exchange, and normal physiological functioning (Woodrow et al. 1988, Outlaw and De Vlieghere-He 2001, Stearns and Glick 2003, Hall et al. 2006). It is also possible to assume a higher water use efficiency (net photosynthetic rate/transpiration rate) in the TIB plants. The headspace composition is one of the main contributors for in vitro plantlet development (Buddendorf-Joosten and Woltering 1994).

Morphological and physiological changes during the in vitro culture were supported by the analysis of carbon metabolism enzymes. The significant increase of PK activity together with the lower PEPC activity (almost 50 fold) in the GM plantlets are in agreement with Le et al. (2001) who verified that free access to media sugar sources prevails over the primary synthesis by the plant. In TIB, PEPC activity was higher, possibly due to an environment that mimics outdoor conditions, leading directly to high PEPC activity and photosynthetic rate.

Starch is the main storage compound in plantain plantlets, with a concentration several fold higher in corms than in leaves (Aragón et al. 2006). In plantain plantlets propagated in TIB, sucrose is the less important storage form in leaves, further enhancing the importance of starch accumulation and sugar mobilization from corm to leaves in the first days of the ex vitro phase (Aragón et al. 2006). Leaves can also accumulate starch during the day, the reserves to meet the demands of the plants during night (Capellades et al. 1991). It is possible that starch accumulation in the corm depends on an endogenous regulation independent of external factors since in the present work there were no differences between the GM and TIB plantlets. Nevertheless, the starch content in leaves was higher in TIB than in GM due to the higher net photosynthetic rate in the TIB plantlets. During the first days of ex vitro growth, plantlets consume their starch reserves, as reported in the other plant species (Capellades et al. 1991, Van Huylenbroeck et al. 2000, Carvalho et al. 2002, Carvalho and Amâncio 2002).

GM plantlets have a higher respiration rate than TIB plantlets, using the sucrose available in the culture media as the basic energy source. The PK activity was 28 -fold higher than the PEPC activity in GM, what points to an extremely high catabolic metabolism. The glycolytic 
activity supported by the high PK activity compensated the lack of ATP generation by photosynthesis. It is well known that totally closed systems are more stressful than partially closed systems, such as TIB (Ziv 2005).

No significant change in $P K$ expression during the transition to autotrophy was observed in the GM plantlets, just a tendency to an initial down-regulation that recovered thereafter whereas in TIB plantlets $P K$ was down-regulated. Unlike in GM plantlets, a significant down-regulation of $P E P C$ expression in the initial period of acclimatization in the TIB plantlets confirms the stepwise increase of photosynthetic metabolism in ex vitro conditions (Aragón et al. 2005). The strong downregulation of $S S$ in the TIB plants could be related with the high starch content in leaves of these plantlets. As a whole, the TIB grown plantlets are better adjusted to an autotrophic environment.

Upon exposure to the stress caused by the transfer to ex vitro conditions, plantain plants develop an efficient ROS scavenging system (Aragon et al. 2010). Among others, Prxs are described as efficient ROS detoxification systems in the chloroplasts, mitochondria and even nucleus, but also as key players in redox signaling during plant development and environmental acclimation (Dietz 2002, 2003). Each Prx has a distinct role and cellular localization. Prx E is present in the chloroplast stroma in very low concentrations, whereas Prxs $Q$ and $F$ have a more prominent role in chloroplasts and mitochondria, respectively (Dietz 2011). In previous research, we showed that polymerization of Prxs E and F is observed in the TIB propagated plants (Aragon et al. 2010). A variety of isoforms of Prxs E, F, and Q were clearly identified in TIB plants with higher pI diversity in Prx E and without polymerization patterns in Prx F. Molecular masses for Prx monomers vary between 17.4 and $29.6 \mathrm{kDa}$ and some form dimers, tetramers, and octamers, and their pIs are between 4.71 and 6.29 (Dietz 2003). The

\section{References}

Aragón, C., Carvalho, L., González, J., Escalona, M., Amâncio,S.: Ex vitro acclimatization of plantain plantlets micropropagated in temporary immersion bioreactor. Biol.Plant. 54: 237-244, 2010.

Aragón, C., Escalona, M., Capote, I., Pina, D., Cejas, I., Rodríguez, R., Cañal, M., Sandoval, J., Roels, S., Debergh, P., González-Olmedo, J.: Photosynthesis and carbon metabolism in plantain (Musa AAB) growing in temporary immersion bioreactor (TIB) and ex vitro acclimatization. In Vitro cell. dev. Biol. Plant 41: 550-554, 2005.

Aragón, C., Escalona, M., Capote, I., Pina, D., Cejas, I., Rodríguez, R., Cañal, M., Sandoval, J., Roels, S., Debergh, P., González-Olmedo,J.: [Acclimatization of plantain "CEMSA 3/4 (AAB)" plants propagated in temporary immersion system. The role of starch on the acclimatization process.] - INFOMUSA 1-2: 32-35, 2006. [In Span.]

Aragón, C., Escalona, M., Rodriguez, R., Cañal, M., Capote, I.,Pina, D., González, J.: Effect of sucrose, light, and carbon dioxide on plantain micropropagation in temporary immersion bioreactors. - In Vitro cell. dev. Biol. Plant 46: results of $\mathrm{pI}$ and polymerization of Prxs reflect their cellular compartmentalization between chloroplast and mitochondria. The quantification of the expression of the respective genes show that at the end of acclimatization, Prxs $E$ and $F$ were down-regulated in GM plants, whereas $\operatorname{Prx} Q$ was up-regulated in TIB. Even though a direct relationship cannot be established between the gene expression and the enzyme activity in the cell due to the processes taking place between mature RNA formation and enzyme synthesis in the active form, in TIB grown plants the gene expression results mentioned above connect the up-regulation of the expression of Prx $Q$ with the respective protein. In unstressed plants, and in plants not being able to respond to a stress, $\operatorname{Prx} Q$ is only expressed in leaves, but not in roots or stems, and the expression is very low (Rouhier et al. 2004). Thus, it is likely that the significant up-regulation of $\operatorname{Prx} Q$ and the high enzyme activity observed in the TIB grown plants was related to the need to keep hydrogen peroxide concentrations low in order to better overcome the oxidative stress. In fact, the plant oxidative stress defense system during the in vitro - ex vitro transition was documented before (Carvalho et al. 2006, Bat'ková et al. 2008, Dias et al. 2013).

In conclusion, the plantlets from the TIB system, which accumulates less ethylene in the headspace, exhibited better growth, lower stomata conductance, and higher photosynthetic rate. Conversely, the GM plants had lower photosynthetic rate and higher PK activity. Further, the TIB grown plantlets accumulated more starch in the leaves which could be used during the first days of the ex vitro acclimatization. The occurrence of the different Prx isoforms and the up-regulation of the $\operatorname{Prx} Q$ expression are further elements that indicate better antioxidative performance and thus justify the advantages of the TIB method for producing better quality plants.

89-94, 2009.

Bat'ková, P., Pospíšilová, J., Synková, H.: Production of reactive oxygen species and development of antioxidative systems during in vitro growth and ex vitro transfer. - Biol. Plant. 52: 413-422, 2008.

Bello-Pérez, L., Contreras-Ramos, S., Romero-Manilla, R., Solorza-Feria, J., Jiménez-Aparicio, A.: [Functional chemistry properties of modified starch from plantain Musa paradisiaca L. (male clone).] - Agrochemical 36: 169-180, 2002. [In Span.]

Bradford, M.: A rapid and sensitive method for the quantification of microgram quantities of protein utilizing the principle of protein dye binding. - Anal.Biochem. 72: 248-254, 1976.

Buddendorf-Joosten, J., Woltering, E.: Components of the gaseous environment and their effects on plant growth and development in vitro. - Plant Growth Regul. 15: 1-16, 1994.

Capellades, M., Lemeur, L., Debergh, P.: Effects of sucrose on starch accumulation and rate of photosynthesis in Rosa culture in vitro. - Plant Cell Tissue Organ Cult. 25: 21-26, 
1991.

Carvalho, L., Amâncio, S.: Effect of ex vitro conditions on growth and acquisition of autotrophic behaviour during the acclimatization of chestnut regenerated in vitro. - Sci. Hort. 95: 151-164, 2002

Carvalho, L., Santos, P., Amâncio, S.: Effects of light intensity and $\mathrm{CO}_{2}$ concentration during the acclimatization of in vitro grapevine. - Vitis 41: 1-6, 2002.

Carvalho, L.C., Vilela, B.J., Vidigal, P., Mullineaux, P.M., Amâncio, S.: Activation of the ascorbate-glutathione cycle is an early response of micropropagated Vitis vinifera L. explants transferred to ex vitro. - Int. J. Plant Sci. 167: 759$770,2006$.

Cayón, G.: [Evolution of photosynthesis, transpiration and chlorophyll during the plantain (Musa AAB Simmonds) leaf growth.] - INFOMUSA 10: 12-15, 2001. [In Span.]

Chang, S., Puryear, J., Cairney, J.: A simple and efficient method for isolating RNA from pine trees. - Plant mol. Biol. Rep. 11: 113-116, 1993.

Coito, J., Rocheta, M., Carvalho, L., Amâncio,S.: Microarraybased uncovering reference genes for quantitative real time PCR in grapevine under abiotic stress. - BMC Res. Note 5: 220, 2012.

Dias, M.C., Pinto, G., Correia, C.M., Moutinho-Pereira, J., Silva, S., Santos, C.: Photosynthetic parameters of Ulmus minor plantlets affected by irradiance during acclimatization. - Biol. Plant. 57: 33-40, 2013.

Dietz, K.-J.: Plant peroxiredoxins. - Annu. Rev. Plant Biol. 54: 93-107, 2003

Dietz, K.-J.: Peroxiredoxins in plants and cyanobacteria. Antioxid. Redox Signal. 15: 1129-1159, 2011.

Dietz, K.-J., Horling, F., Konig, J., Baier, M.: The function of the chloroplast 2-cysteine peroxiredoxin in peroxide detoxification and its regulation. - J. exp. Bot. 53: 13211329,2002

Escalona, M., Cejas, I., Gonzalez-Olmedo, J., Capote, I., Roels, S., Cañal, M.J., Rodríguez, R., Sandoval, J., Debergh, P.: [The effect of meta-topolin on plantain propagation using a temporary immersion bioreactor.] - INFOMUSA 12: 28-30, 2003. [In Span.]

Escalona, M., Lorenzo, J., González, B., Daquinta, M., Borroto, C., González, J., Desjardins,Y.: Pineapple micropropagation in temporary immersion systems. - Plant Cell. Rep. 18: 743748, 1999.

Etienne, E., Berthouly, M.: Temporary immersion systems in plant micropropagation. - Plant Cell Tissue Organ Cult. 69: 215-231, 2002

Ferreira, R., Franco, E., Teixeira, A.: Covalent dimerization of ribulosebisfosphate carboxylase subunits by UV radiation. Biochem. J. 318: 227-234, 1996.

Geigenberger, P., Stitt, M.: A "futile" cycle of sucrose synthesis and degradation is involved in regulating partitioning between sucrose, starch and respiration in cotyledons of germinating Ricinus communis L. seedlings when phloem transport is inhibited. - Planta 185: 81-90, 1991.

Hall, M., Kapuya, J., Sivakumaran, S., John, A.: The role of ethylene in the response of plants to stress. - Pestic. Sci. 8: 217-223, 2006.

Hazarika, B.: Acclimatization of tissue-cultured plants. - Curr. Sci. 85: 1704-1712, 2003.

Hdider, C., Desjardins, Y.: Effects of sucrose on photosynthesis and phosphoenolpyruvate carboxylase activity of in vitro culture strawberry plantlets. - Plant Cell Tissue Organ Cult. 36: 27-33, 1994.

Laemmli, U.K.: Cleavage of structural proteins during the heat of bacteriophage T4. - Nature 227: 680-685, 1970

Larema, L., Ferreira, A., Witt, C., Carnevalli, L., Fontes, R., Jardim, E., Campos, W.: Photoautotrophic propagation of Brazilian ginseng [Pfaffiaglomerata (Spreng.) Pedersen]. Plant Cell Tissue Organ Cult. 110: 227-238, 2012.

Le, Q.V., Samsom, G., Desjardins, Y.: Opposite effects of exogenous sucrose on growth, photosynthesis and carbon metabolism of in vitro plantlets of tomato (L. esculentum Mill.) grown under two levels of irradiances and $\mathrm{CO}_{2}$ concentrations. - J. Plant Physiol. 158: 599-605, 2001.

Lin, M., Turpin, D., Plaxton, W.: Pyruvate kinase isoenzymes from green alga Selenastrum minutum. I. Purification and physical and immunological characterization. - Arch. Biochem. Biophys. 269: 219-227, 1989.

Lorenzo, J., Blanco, M., Peláez, O., González, A., Cid, M., Iglesias, A., González, B., Escalona, M., Espinosa, P., Borroto, C.: Sugarcane micropropagation and phenolic excretion. - Plant Cell Tissue Organ Cult. 65: 1-8, 2001.

Ma, S., Shii, C.: Growing banana plantlets from adventitious buds. - J. chin. Soc. hort. Sci. 20: 6-12, 1974.

Martín, A., Casas, J., Piqueras, A.: Nitrogen assimilating enzymes during acclimatization of micropropagated Musa sp. plants. - Acta hort. 812: 421-42, 2009.

Moreira, F., Borghezan, M., Lima, A.: Assessment of the carbon dissimilation methodology in the in vitro growth of the 'Paulsen 1103' grapevine. - Crop Breed. appl. Biotechnol. 3: 157-162, 2003.

Murashige, T., Skoog, F.: A revised medium for rapid growth and bioassays whit tobacco tissue cultures. - Physiol. Plant. 15: 473-497, 1962.

Nakamura, S., Nitta, Y., Watanabe, M., Goto, Y.: Analysis of leaflet shape and area for improvement of leaf area estimation method for sago palm (Metroxylon sagu Rottb.). - Plant Prod. Sci. 8: 27-31, 2005.

Outlaw, J., De Vlieghere-He, X.: Transpiration rate. An important factor controlling the sucrose content of the guard cell apoplast of broad bean. - Plant Physiol. 126: 17161724,2001

Panis, B., Thinh, N.: Cryopreservation of Musa Germplasm. INIBAP Technical Guidelines 5. INIBAP, Montpellier 2001.

Pérez, C.: Statistical Methods in SPSS 12. Applications to Data Analysis. - Prentice Hall, Madrid 2005.

Perveen, S., Anis, M., Aref, I.M.: Lipid peroxidation, $\mathrm{H}_{2} \mathrm{O}_{2}$ content, and antioxidants during acclimatization of Abrus precator to ex vitro conditions. - Biol. Plant. 57: 417-424, 2013.

Ramagli, L.: Quantifying protein in 2D PAGE solubilization buffers. - In: Link A.J. (ed): Methods in Molecular Biology - 2D Proteome Analysis Protocols. Pp. 112. Humana Press, Totowa 1999.

Roels, S., Escalona, M., Cejas, I., Noceda, C., Rodríguez, R., Cañal, M., Sandoval, J., Debergh, P.: Optimization of plantain (Musa AAB) micropropagation by temporary immersion system. - Plant Cell Tissue Organ Cult. 82: 5766, 2005.

Roels, S., Noceda, C., Escalona, M., Sandoval, J., Cañal, M., Rodríguez, R., Debergh, P.: The effects of headspace renewal in a temporary immersion biorreactor on plantain (Musa AAB) shoot proliferation and quality. - Plant Cell Tissue Organ Cult. 84: 138-146, 2006.

Rouhier, N., Gelhaye, E., Gualberto, J.M., Jordy, M.N., De Fay, E., Hirasawa, M., Duplessis, S., Lemaire, S.D., Frey, P., Martin, F., Manieri, W., Knaff, D.B., Jacquot, J.-P.: Poplar peroxiredoxin Q. A thioredoxin-linked chloroplast 
antioxidant functional in pathogen defense. - Plant Physiol. 134: 1027-1038, 2004.

Siegel, G., Stitt, M.: Partial purification of two forms of spinach leaf sucrose-phosphate synthase which differ in their kinetic properties. - Plant Sci. 66: 205-210, 1990.

Stearns, J., Glick, B.: Transgenic plants with altered ethylene biosynthesis or perception. - Biotechnol. Adv. 21: 193-210, 2003.

Teisson, C., Alvard, D.: A new concept of plant in vitro cultivation liquid medium: temporary immersion. - In: Terzi, M., Celia, R., Falavigna, A. (ed.): Current Issues in Plant Molecular and Cellular Biology. Pp. 105-110. Kluwer Academic Publishers, Dordrecht 1995.

Thomas, W., Rufty, J., Steven, C.: Changes in starch formation and activities of sucrose phospate synthase and cytoplasmic fructose-1-6-bisphosphatase in response to source-sink alterations. - Plant Physiol. 72: 474-480, 1983.

Van Handel, E.: Direct microdetermination of sucrose. - Anal. Biochem. 22: 280-283, 1968.

Van Huylenbroeck, J., Piqueras, A., Debergh, P.C.: The evolution of photosyntesis capacity and the antioxidant enzymatic system during acclimatization of micropropagated Calathea plantlets. - Plant Sci. 155: 59-66, 2000.

Woodrow, L., Thompson, R., Grodzinski, B.: Effects of ethylene on photosynthesis and partitioning in tomato, Lycopersicon esculentum Mill. - J. exp. Bot. 39: 667-684, 1988.

Ziv, M.: Simple bioreactors for mass propagation of plantlets. Plant Cell Tissue Organ Cult. 81: 277-285, 2005. 